\title{
A New de Novo Mutation Associated with Neurofibromatosis (NF-1)
}

\author{
José Guevara González ${ }^{1 *}$, Isabel Dimas Rendón ${ }^{1}$, Marisol Vilamizar ${ }^{1}$, José Guevara Campos ${ }^{1}$ and Lucía Guevara González $^{2}$ \\ ${ }^{1}$ Pediatric Departament of Hospital, "Felipe Guevara Rojas", University Oriente, El Tigre, Anzoátegui, Venezuela \\ ${ }^{2}$ Epilepsy Unit and Electroencephalography, El Tigre, Anzóategui, Venezuela
}

"Corresponding author: José Guevara Campos, Pediatric Departament of Hospital, “Felipe Guevara Rojas”, University Oriente, El Tigre, Anzoátegui, Venezuela, Tel: +58 0283-04148457662; E-mail: Joguevar90@hotmail.com

Received date: June 30, 2016; Accepted date: July 27, 2016; Published date: Aug 02, 2016

Copyright: @ 2016 González JG, et al. This is an open-access article distributed under the terms of the Creative Commons Attribution License, which permits unrestricted use, distribution, and reproduction in any medium, provided the original author and source are credited.

\begin{abstract}
Neurofibromatrosis type 1 (NF-1) in the most common neurocutaneous disease with a autosomal dominant inheritance pattern and a frequency of 1:3.500 lives births in the general population, regardless of race and sex. NF-1 is a progressive disorder characterized by multiples café-au-lait macules, neurofibromas, Lish nodules and others manifestations such as bone abnormalities, short stature, epilepsy, learning disabilities, hyperactivity, with a highly variable and unpredictable expression. Half of its cause comes from different mutations in a gene on chromosome 17, resulting in less or performance neurofibromin having the regulatory domain of tumor activity. The other $50 \%$ of the case are caused by de novo mutation.
\end{abstract}

It is an infant 13 months old, no family history of neurofibromatosis, which features six café-au lait spots $1 \mathrm{~cm}$ of diameter in the legs, chest, auxiliary region a and short stature.

The clinical diagnostic criteria of NF-1 were established by The National Institutes Heath Consensus Development Conference in 1987. It has been suggested that pathogenic mutation in the NF-1 gene be added to the list of diagnostic criteria, but not yet accepted.

A molecular genetics study showed an alteration in exon 16 c.2540T>G (p.Leu847 Arg). No genetic alterations found in phenotypic parents.

After six year of follow-up she was not observed clinical or radiographic abnormalities.

The genetic study is mandatory for confirmation of the suspected diagnosis and to monitor de novo mutations that knowledge and phenotypic expression thereof.

Keywords: Gene; Café-au-lait macules; Mutation; disabilities, hyperactivity, short stature, hydrocephalus, scoliosis, Neurofibromatosis; Neurofibromin; Genetic epilepsy, headaches, bone abnormalities and cardiovascular lesions [6].

\section{Introduction}

In 1988 the clinical criteria for the diagnosis of NF-1 are at least 2 of the following criteria: 1) Six or more café-au-lait macules with

The NF-1 was described by Von Recklinghausen in 1882, a German pathologist who recognized that tumors observed in the skin were composed of fibrous tissue surrounding the nerves, resulting in the name of neurofibroma [1]. NF-1 is the most common mendelian dominant autonomic disorder with a variable and unpredictable expression, caused by a mutation that inactivates the germline in a gene on chromosome 17q11.2 [2].

Clinical manifestations are the latte spots are the first sign in the affected children present at birth or in the first months of life, are flat brownish lesions of varying intensity, with a diameter of $0.5 \mathrm{~cm}$, is found throughout the body except the scalp, eyebrows, and palms of hands and soles of the feet [3].

The freckles are spots smaller location in the armpits or groin and are not present at birth, appear between $3-5$ years $[3,4]$. Cutaneous or subcutaneous neurofibromas and Lisch nodules or iris hamartomas appear within 5-10 years [3,5]. Other manifestations are learning diameters $>5 \mathrm{~mm}$ in prepubertal patients and $>15 \mathrm{~mm}$ in postpubertal patients; 2) Two or more neurofibromas of any type or one plexiform neurofibroma; 3) Axillary or inguinal freckling; 4) Optic glioma; 5) Two or more Lisch nodules of the iris; 6) A distinctive osseous lesion, such as sphenoid wing dysplasia or pseudarthrosis; 7) A father or brother diagnosed with neurofibromatosis established [7].

The gene was identified by Cawthon [8] with positional cloning techniques, have been shown translocations, deletions and point mutations of the NF-1 gene on chromosome 17q11.2, chromosomal assignment previously established by genetic analysis of families carrying neurofibromatosis [8]. The NF-1 gene, $300 \mathrm{~Kb}$ consists of 60 exons in genomic DNA, mRNA encoding a 11-13 Kb and specifies a cytoplasmic localization protein, neurofibromin 2818 amino acids and $327 \mathrm{kD}$ molecular weight [9].

The mutation rate for NF-1 is one of the highest known, probably due to large size of the gene conversions mediated genes and pseudogenes presence of repeated sequences [10]. In the present is considered that half of patients diagnosed with NF-1 are a spontaneous 
mutation de novo where parents have no chromosomal abnormality, nor have the disease so there is talk of germline mutations [11,12].

Having identified a new de novo mutation in the gene for neurofibromatosis, a Venezuelan girl, motivated us to conduct this work. We to mark again the importance of molecular genetics study in clinically diagnosed patients to detect new mutations or simply to establish the evolution and behavior of the detected mutation.

\section{Clinical case}

The Infant 13 months, female who presents café-au-lait spots in various parts of the body and short stature.

Antecedent Important: One product gestation, pregnant 38 weeks to term controlled, obtained by cesarean, no consanguineous parents. Birth weight: $2900 \mathrm{Kg}$; Stature: $49 \mathrm{~cm}$. Normal psychomotor development.

Physical examination: Weight: $10 \mathrm{~kg}$ (50th percentile) Stature: 69 $\left(<10^{\text {th }}\right.$ percentile) Head circumference: $46 \mathrm{~cm}$ (50th percentile).

In the time of admission was in good general condition, no dysmorphic features were seen, they were observed skin six café au lait macules, flat oval greater than $1 \mathrm{~cm}$ in diameter in the lower limbs, chest and inguinal regions. Cardiopulmonary was normal. Abdomen no tumors were observed, nor visceromegaly. The tendon reflexes normal. Neurological was normal. Evaluation dermatological was confirmed the NF-1.

Laboratory Tests: See Table 1.

\begin{tabular}{|l|l|}
\hline Hemoglobin & $11.7 \mathrm{gr} / \mathrm{dL}$ \\
\hline Hematocrit & $39 \%$ \\
\hline Leukocytes & $5000 \mathrm{mM}$ \\
\hline Segmented & $37 \%$ \\
\hline Lynphocytes & $63 \%$ \\
\hline Glucose & $78 \mathrm{mg} / \mathrm{dL}$ \\
\hline Urea & $14 \mathrm{mg} / \mathrm{dL}$ \\
\hline Creatinine & $4 \mathrm{mg} / \mathrm{dL}$ \\
\hline T3 & $3.37 \mathrm{ng}(\mathrm{dL}$ \\
\hline T4 & $1.50 \mathrm{ng} / \mathrm{dL}$ \\
\hline Oxalaocetic Transaminase & $7.1 \mathrm{U} / \mathrm{L}$ \\
\hline Piruvica & $18 \mathrm{U} / \mathrm{L}$ \\
\hline Transaminase & $9 \mathrm{mg} / \mathrm{dL}$ \\
\hline Calcium &
\end{tabular}

Table 1: Laboratory tests.

Chest radiography was normal, brain MRI was normal. Evaluation ophthalmological was normal.

Molecular genetics study for direct cycle sequencing of NF1 exon 16, was practiced in UAB Medical Genomics Laboratory (Dr Ludwine Messiaen) showed an alteration in exon 16 c.2540T $>$ G (p.Leu847Arg).
A heterozygous missense alteration in exon 16 of the NF-1 gene was identified in the patient c2540T>G (p.Leu847 Arg).

This alteration was noted reported before and we have never observed it in our cohort of patients and controls.

We have finalized analysis in the parents, both reported to be an unaffected and did not find the missense alteration c.2540T $>\mathrm{G}$ (p.Leu847 Arg) in them.

This indicates that c.25OT>G (p.Leu847 Arg) occurred de novo in the patient. Taking into account all evidence available at this time, we conclude that the missense alteration is very likely a pathogenic mutation.

The genetic study was performed both parents giving negative for the disease NF-1.

\section{Discussion}

NF-1 is a common dominant multisystem progressive disease, autosomal with complete penetrance, which occurs in childhood with heterogeneous manifestations [13]. The earliest and most common manifestations are café au lait spots that are present at birth or appear in the first months, which are detected by a simple visual inspection, as in our patient [14].

The distribution of the symptoms and signs of multisystem or behavior may be related to the defect in the protein neurofibromin at various stages of differentiation of the affected cells. The clinical features are highly variable even within a family, some children just have areas of skin hyperpigmentation (spots), but others suffer severe and disabling involvement characterized by central nervous system tumors, scoliosis, dysplasia of long bones, peripheral vascular lesions and rapidly growing tumors that can cause dysfunction and disfigurement [15].

The most common complications are short stature, which was found in the patient. The penetrance of neurofibromatosis is $100 \%$ means that all patients with neurofibromatosis NF-1 have a mutation. A molecular genetic analysis can detect a genetic mutation in over $92 \%$ of the examined patients who meet the diagnostic criteria. It is very important in children with negative family history and that only partially meet the diagnostic criteria [16].

The mutation rate in germ cells, calculated for gene NF1 neurofibromatosis type is one of the highest reported in humans, is above $50 \%$ of cases are due to de novo mutations. Mutations of neurofibromatosis type 1 appear to be evenly distributed along the gene. However some exons have a density higher mutation and most of these are recurrent mutations. Therefore these exons may have priority in mutation detection [10].

Although several mutations descriptions, there is no clear phenotype-genotype correlation, except NF1 patients with neurofibromatosis type, due to a complete deletion of the NF1 gene [15]. The wide variability of phenotype expression, even among affected members of my own family, is another hallmark of neurofibromatosis type 1 neurofibromatosis mild forms of mosaicism is caused by a situation in which the NF-1 mutation occurs after fertilization.

Somatic mutations occur early during embryonic development and produce a generalized mosaicism which is characterized by a slight indistinguishable form of the classical form of type 1 [14] 
neurofibromatosis. Gonadal mosaicism is a rare form of mosaicism, the mutation is present only in the gonads and may be suspected in children with NF-1 unaffected parents, or family history, as in our case.

In a study by Yunus et al. [10] analyzing $4 \mathrm{~b}$ exon were performed, $16,29,31$ and 37 to investigate recurrent mutations in 100 patients in Turkey with neurofibromatosis type NF1, these analysis allowed to identify two different mutations in exon 4b, 496delGT and 499delTGTT and unknown mutation in exon 31, 5866deIA. Han et al, found three mutations in exon $4 \mathrm{~b}$ but none in exon 37.

Messiaen et al. [16] describes a comprehensive analysis of mutations in the NF1 neurofibromatosis type, $30 \%$ of the mutations found in their study were recurrent. These data support the contention that different populations have different sets of exons that contain recurrent mutation.

The molecular test to NF-1 is also useful in confirming the diagnosis in the case in patients with café-au-lait spots $(98 \%)$ and with or without freckling (30\%) and absence of a high prevalence of nervous system tumors Central [17]. They may be associated with learning disabilities and behavioral problems such attention disorder/ hyperactivity (TADH) but with less severe than NF1 [18-20] cognitive phenotype. Dysmorphic features as macrocephaly (42\%), short stature and less frequent Noonan-like facial features, achromic spots, pectus excavatum, headache, convulsions, deafness, scoliosis.

In these patients with a mild phenotype but with the diagnostic criteria for NF1 successful, they could have a Legius syndrome or NF1like described in 2007 by Breems et al [21], which is due to an autosomal dominant mutation in the SPRED1 gene in the $15 \mathrm{q} 13.2$ chromosome which implies a loss of function of proteins involved in the pathogenic pathway RAS-MAPK1, neurofibromin like and therefore can be considered as a rasphathy [22].

Approximately at $1-2 \%$ of patients with neurofibromatosis criteria for NF1 has mutations in SPRED1 [18]. In addition this gene described a potential increased risk of developing leukemia (17.22) SPRED1 that the gene is also expressed in hematopoietic cells that down regulate the process of hematopoietic by suppressing stem cell stimulating factor and interleukin [17].

Early detection is a better prognosis and to evaluate the clinical follow these novo mutations that allow phenotypic knowledge of them and the expression of the disease.

The case presented was a minimal expression of the disease.

Throughout this reason it is important that pediatricians, pediatric neurologists, geneticist, dermatologists, ophthalmologists and oncologists who are involved in the diagnosis and treatment of patients with NF-1, forces us to change the management of patients with caféau-lait spots and perform molecular genetics study.

\section{References}

1. Rynolds RM, Browning GG, Nawroz I, Campell IW (2003) Von Recklinghausen's neurofibromatosis: neurofibtomatosis type 1. Lancet 361: 1552-1554
2. Upadhyaya M (2008) NF1 gene structure and NF1 genotype/phenotype correlations. In: Basel K (ed.) Neurofibromatosis Kaufmann. Karger pp: 46-62.

3. Korl BR (2002) Clinical features and pathology of neurobibromatosis 1. J Child Neurol 17: 548-554.

4. Friedman JM, Ricardi VW (1999) Clinical and epidemiological features In: Neurofibromatosis: Phenotype, Natural History, and Pathogenesis. 3rd ed. Baltimore, MD: John Hopkins University Press pp: 29-86.

5. Williams VC, Lucas J, Babcock MA, Gutmann DH, Korf B, et al. (2009) Neurofibromatosis Type 1 Revisisted. Pediactrics 123: 139.

6. Ferner R (2010) The Neurofibromatosis. Pract Neurol 10: 83-93

7. National Institutes of Health (1987) Consensus Development Conference Statement: Neurofibromatosis, Bethesda Md. USA. Neurofibromatosis 1: 172-178.

8. Cawthon RM, Weiss M, Xu G (1990) A major segment of the Neurofibromatosis type 1 gene: cDNA sequence, genomic structure and point mutations. Cell 62: 193-201.

9. Marchuck DA, Saylino AM, Travakkol R, Swaroop M, Wallace MR, et al. (1991) CDNA cloning of the type 1 neurofibromatosis gene: complete sequence of the Nf1 gene product. Genomics 11: 931-940.

10. Yunus K, Sibel O, Banu A, Sabiha A, Surkriye A (2007) Neurofibromatosis: Novel and Recurrent Mutations in Turkish Patients. Pediatric Neurology 37: 421-425.

11. Valero CM, Viejo PCI, Velasco E, Moreno F, Hernandez-Chico C (1997) Identification of de novo delections at the NF-1 gene: No preferential paterm origin and phenotypic analyses of patients. Hum Genet 99: 720-726.

12. Upadhyaya M, Majounie E, Thompson P, Han S, Consoli C, et al. (2003) Three different pathological lesions in the NF-1 gene originating de novo in a family with Neurofibromatosis type 1. Hum Genet 112: 12-17.

13. North K (2000) Neurofibromatosis Type 1. Am J Med Genet 97: 119-127.

14. Eeva MJ, Sirkku P, Antohony M, Juha P (2011) The Pathoetiology of Neurofibromatosis 1. Am J Pathol 178: 1932-1939.

15. Eric P, Michel V, Dominique V, Pierre W (2012) Neurofibromatosis type 1: from genotype to phenotype. J Med Genet 49: 483-489.

16. Messiaen L, Wimmer K (2008) NF-1 mutation spectrum In: Basel K (ed.) Neurofibromatosis. Karger pp: 63-77.

17. Pasmant E, Ballerini P, Lapillonne H, Perot C, Vidaud, et al. (2009) SPRED1 disorder and predisposition to leukemia in Children. Blood 114: 1131.

18. Messiaen L, Yao S, Breems H, Callens T, Sathienkijkanchai A, et al. (2009) Clinical and mutational Spectrum of Neurofibromatosis type 1-like Syndrome. JAMA 302: 2111-2118.

19. Viejo PC, Pascal-Pascal SI, Velásquez- Fragua R, Viaño J (2012) Tumor del cuerpo calloso como presentación de Neurofibromatosis tipo 1 en un paciente y revisión de la bibliografía. Rev Neurol 55: 528-532.

20. Denayer E, Descheemaker MJ, Stewart DR, Keymolen K, Plasschaert E, et al. (2011) Observations on intelligence and behavior in 15 patients with Legius Syndrome. Am J Med Genet C Semin Med Genet 157: 123-128.

21. Breems H, Chmara M, Sabatou M, Denayer E, Tanaguchi K, et al. (2007) Germile loos- of function mutations in SPRED1 cause a Neurofibromatosis 1 like phenotype. Nat Genet 39: 1120-1126.

22. Cemeli-Cano M, Segura PJL, Martinez RF, Álvarez IS, Galindo ML, et al. (2014) Un nuevo Sindrome neurocutaneo: Sindrome de Legius. A propósito de un Caso. Rev Neurol 59: 209-212. 